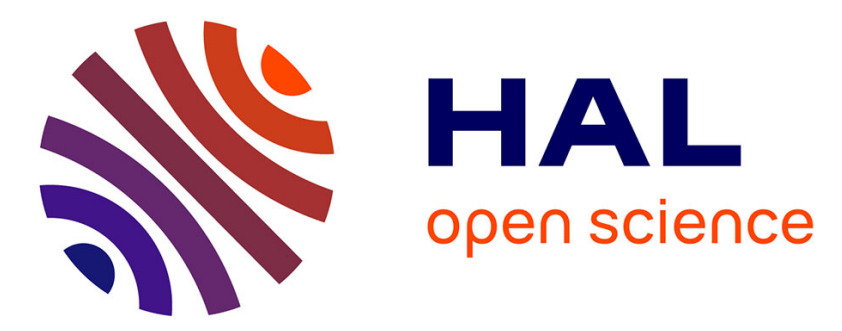

\title{
Maintenance grouping for multi-component systems with availability constraints and limited maintenance teams
}

Phuc Do Van, Hai Canh Vu, Anne Barros, Christophe Bérenguer

\section{- To cite this version:}

Phuc Do Van, Hai Canh Vu, Anne Barros, Christophe Bérenguer. Maintenance grouping for multicomponent systems with availability constraints and limited maintenance teams. Reliability Engineering and System Safety, 2015, 142, pp.56-67. 10.1016/j.ress.2015.04.022 . hal-01151129v2

\section{HAL Id: hal-01151129 \\ https://hal.science/hal-01151129v2}

Submitted on 20 Jul 2015

HAL is a multi-disciplinary open access archive for the deposit and dissemination of scientific research documents, whether they are published or not. The documents may come from teaching and research institutions in France or abroad, or from public or private research centers.
L'archive ouverte pluridisciplinaire HAL, est destinée au dépôt et à la diffusion de documents scientifiques de niveau recherche, publiés ou non, émanant des établissements d'enseignement et de recherche français ou étrangers, des laboratoires publics ou privés. 


\title{
Maintenance grouping for multi-component systems with availability constraints and limited maintenance teams
}

\author{
Phuc Do ${ }^{1,2 *}$, Hai Canh $\mathrm{Vu}^{3}$, Anne Barros ${ }^{4}$ and Christophe Bérenguer ${ }^{5,6}$ \\ ${ }^{1}$ Université de Lorraine, CRAN, UMR 7039, Campus Sciences, BP 70239, Vandoeuvre-les-Nancy, 54506, France \\ ${ }^{2}$ CNRS, CRAN, UMR 7039, France \\ ${ }^{3}$ Université de technologie de Troyes, 12 Rue Marie Curie, BP 2060, Troyes, 10010, France \\ ${ }^{4}$ Department of Production and Quality Engineering, Norwegian University of Science and Technology, Norway \\ ${ }^{5}$ Univ. Grenoble Alpes, GIPSA-lab, F-38000 Grenoble, France \\ ${ }^{6}$ CNRS, GIPSA-lab, F-38000 Grenoble, France \\ *Corresponding author: phuc.do@univ-lorraine.fr
}

\begin{abstract}
The paper deals with a maintenance grouping approach for multi-component systems whose components are connected in series. The considered systems are required to serve a sequence of missions with limited breaks/stoppage durations while maintenance teams (repairmen) are limited and may vary over time. The optimization of the maintenance grouping decision for such multi-component systems leads to a NP-complete problem. The aim of the paper is to propose and to optimize a dynamic maintenance decision rule on a rolling horizon. The heuristic optimization scheme for the maintenance decision is developed by implementing two optimization algorithms (genetic algorithm and MULTIFIT) to find an optimal maintenance planning under both availability and limited repairmen constraints. Thanks to the proposed maintenance approach, impacts of availability constraints or/and limited maintenance teams on the maintenance planning and grouping are highlighted. In addition, the proposed grouping approach allows also updating online the maintenance planning in dynamic contexts such as the change of required availability level and/or the change of repairmen over time. A numerical example of a 20-component system is introduced to illustrate the use and the advantages of the proposed approach in the maintenance optimization framework.
\end{abstract}

Keywords: Multi-component systems, maintenance grouping, availability, repairmen, genetic algorithm, MULTIFIT algorithm.

\section{Introduction}

In the maintenance optimization framework of multi-component systems, grouping maintenance has been introduced, developed and successfully applied for various engineering systems [3, 18, 24]. The main idea 
of the maintenance grouping is to take the advantages of positive economic dependence which implies that combining maintenance activities is cheaper than performing maintenance on components separately, see for instance $[4,7,9,20,30]$.

A major challenge of the maintenance optimization consists in joining the stochastic models regarding the components (state evolution) with the combinatorial problems regarding the grouping of maintenance activities. While a long term or infinite planning horizon can be assumed to solve this problem in case of stable situations, dynamic models have been introduced in order to change the planning rules according to short-term information (e.g. failures and varying deterioration of components, spare parts, etc) using a rolling (finite) horizon approach $[18,28,30]$. This approach is however limited to a class of problems with two significant assumptions: (i) maintenance durations are neglected; (ii) each component is preventively maintained one time in horizon interval. To overcome these limitations, several extensions of the rolling horizon approach have been recently developed in [7, 29]. Nevertheless in such papers, maintenance constraints have not yet been considered. From a practical point of view, it is often impossible to perform all the desirable maintenance actions due to the limitations on maintenance resources, such as maintenance budget and limited maintenance teams (repairmen) $[4,15,19]$. In the other hand, industrial systems are usually required to serve a sequence of missions with given required availability levels or limited breaks/stoppage durations, see $[1,15,11,14,25]$. However, when looking at the literature, no research is found dealing with optimal maintenance strategy considering both system (availability) constraint and limited maintenance resources.

In order to address the above-mentioned issues, the first objective of this work is to propose a dynamic maintenance grouping strategy under the rolling horizon approach for multi-component systems whose components are connected in series. The considered systems are required to serve a sequence of missions with limited breaks/stoppage durations while maintenance teams (repairmen) are limited and may vary over time. It is important to note that when taking into account theses constraints in the maintenance model, determining the optimal maintenance planning requires to solve NP-hard problems. Moreover, when only a limited number of maintenance teams are available to carry out the maintenance of a group of components, a question arises on how to allocate optimally maintenance actions to each maintenance team. To solve these issues, the second objective of the paper is to propose a heuristic optimization scheme implementing a genetic algorithm [10,21] and MULTIFIT algorithm (introduced initially for bin-packing problems by [6]) to determine an optimal maintenance planning. In addition, the proposed approach allows updating the maintenance planning as soon as a short-term information related to a dynamic context such as the change of required availability level and/or the change of maintenance teams over time.

The rest of the paper is organized as follows. Section 2 describes the system, the assumptions associated with inspection, maintenance operations and costs, and the problem statement. Section 3 focuses on the description of the proposed maintenance grouping strategy. The implementation of two optimization algorithms (GA and MULTIFIT) are presented in Section 4. To illustrate the use and the advantages of the proposed maintenance grouping approach, a numerical example of a 20-component system is introduced in 
Section 5. In addition some numerical results are analyzed discussed here. Finally, the last section presents the conclusions drawn from this work.

\section{NOTATION LIST}

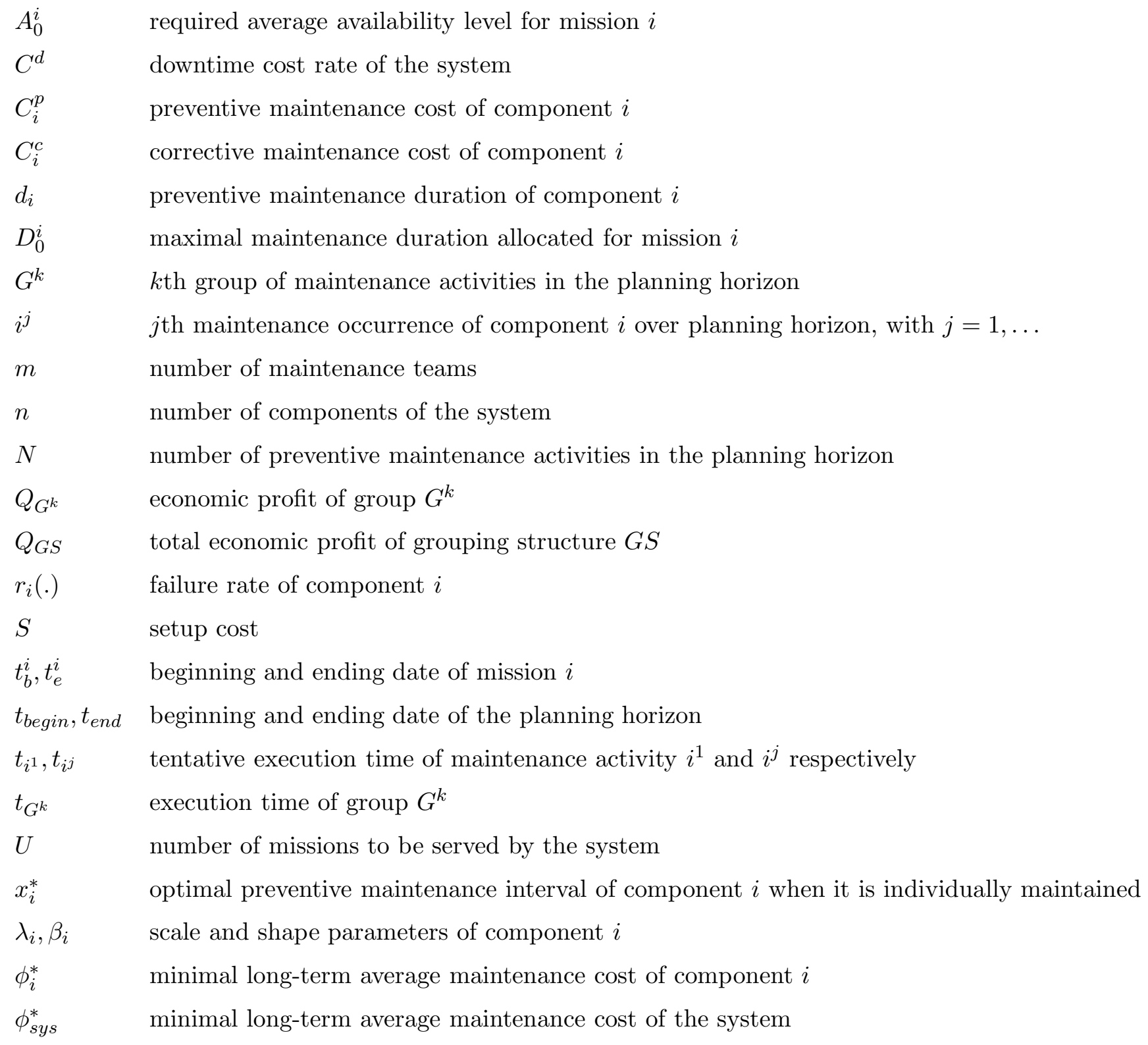

\section{System modeling and problem statement}

Consider a series system consisting of $n$ independent binary components, i.e. a component state is either "operational" or "failed". With this kind of systems, a stoppage of one or more components due to whatever reasons, e.g. failure or maintenance, leads to a shutdown of the system. It is assumed that the failure behavior of components is described by a continuous distribution with increasing failure rate. 


\subsection{Maintenance operations and related costs}

To avoid the failure recurrences of the system, it is assumed that both preventive and corrective maintenance actions are possible for each component. More precisely, if a component fails, it is then immediately repaired with a minimal repair policy. The latter means that a corrective action restores the component involved into a state as bad as old. It is shown $[7,30]$ that, for a minimal repair policy, corrective durations can be very small with respect to maintenance planning horizon and can be neglected. For maintenance cost, it is assumed that a corrective action on component $i$ costs $C_{i}^{c}$.

For preventive maintenance actions, they can usually be planned in advance to prevent failures or/and to reduce maintenance costs. It is assumed that after a preventive action, the maintained component becomes as good as new. This kind of preventive maintenance is also called replacement action. It is shown in [7] that the replacement action may take more time than a minimal repair one and the replacement duration should not be neglected. It is also pointed out in $[7,18,30]$ that the preventive maintenance cost may be shared when performing maintenance on several components together thanks to the economic dependence between components. To highlight this economic dependence, the preventive maintenance cost of the component $i$ is divided in three parts:

- a specific component $\operatorname{cost} c_{i}^{p}$ depending on the component characteristics and maintenance labor costs;

- a setup-cost, denoted $S$, indicates the preparation cost (or logistic cost) and can be shared when several maintenance activities are performed together since execution of a group of maintenance activities usually requires only one set-up [30, 7, 3];

- an unavailability cost: since the system is unavailable during maintenance execution, therefore, if a preventive maintenance of component $i$, so-called activity $i$, leads a shutdown of the system during $d_{i}$ time units, an additional cost or unavailability $\operatorname{cost} c_{i}^{d}=d_{i} \cdot C^{d}$ related to the production loss within $d_{i}$ time units is incurred ( $C^{d}$ is the unavailability cost rate of the system). This additional cost can be also shared when several maintenance activities are simultaneously executed.

As a consequence, if activity $i$, is individually performed, we have to pay the following preventive cost:

$$
C_{i}^{p}=S+c_{i}^{p}+c_{i}^{d}
$$

The economic dependence between components will be investigated and integrated in the proposed grouping approach presented in Section 3.

\subsection{Maintenance constraints and dynamic contexts}

Availability constraints Assume that the system has to serve a sequence of $U$ missions. Each mission $i(i=1, \ldots, U)$ is characterized by three parameters: $t_{b}^{i}, t_{e}^{i}$ and $A_{0}^{i}$ :

- $t_{b}^{i}, t_{e}^{i}\left(t_{b}^{i}<t_{e}^{i}\right)$ represent the beginning and ending date of mission $i$. It is assumed that $t_{e}^{i}=t_{b}^{i+1}$;

- $A_{0}^{i}\left(0<A_{0}^{i} \leq 1\right)$ indicates the average availability level required for mission $i$. 
In that way, the total operating time required for mission $i$ is not lower than $A_{0}^{i} \cdot\left(t_{e}^{i}-t_{b}^{i}\right)$. The latter means that the total stoppage time of the system within mission $i$ is equal or lower than $\left(1-A_{0}^{i}\right) \cdot\left(t_{e}^{i}-t_{b}^{i}\right)$. As mentioned above, corrective maintenance is immediate while preventive maintenance requires a stoppage time of the system. Therefore, if the total stoppage time of the system during the mission $i$ is allocated for preventive maintenance activities, the total preventive maintenance duration within mission $i$, denoted $D^{i}$, must be bounded:

$$
D^{i} \leq\left(1-A_{0}^{i}\right) \cdot\left(t_{e}^{i}-t_{b}^{i}\right)=D_{0}^{i}
$$

where $D_{0}^{i}$ is the maximum duration allowed for all preventive maintenance actions during mission $i$. Since the required average availability level $A_{0}^{i}$ can be directly transformed to the maximum allowed maintenance duration $D_{0}^{i}$, both terminologies are used through the paper.

Limited repairmen To execute preventive activities, we suppose that only $m$ repairmen are available and each repairman can take only one preventive activity at a time.

Dynamic contexts From a practical point of view, the number of repairmen may, be in one hand, changed over time due to economical/technical reasons. In the other hand, the requirement on total operating time for a given mission may be also changed with time. These kind of situations, which are referred to, in this paper, as "dynamic contexts", may have significant influence on the maintenance planning and cost and should be taken into account in the maintenance optimization process. It should be noticed that other kinds of dynamic contexts such as maintenance opportunities, changes in production planning, changes in the system structure have been investigated in maintenance optimization, see [7, 29].

\subsection{Need for dynamic maintenance grouping}

We are here interested in a maintenance grouping strategy according to two following reasons:

1. it is shown in a number of papers, see for example $[4,30]$, that grouping can save maintenance costs since the set-up cost and the unavailability cost can be shared when several maintenance activities are executed together. It must be noticed however that when several maintenance activities are performed together, maintenance cost could be indirectly penalized

- with the reduction of components useful life if the maintenance dates are advanced;

- with the increasing of components failure probability which could imply a system immobilization if the maintenance dates are too late.

2. due to the availability constraint (or limited maintenance duration constraint), several maintenance activities have to be simultaneously performed to reduce maintenance durations. The latter is needed even when it may lead to a higher maintenance cost in some cases, e.g., when the set-up cost and unavailability cost rate are equal to zero, grouping is then more costly but without grouping the required availability level may not be reached. 
In addition, such a maintenance grouped planning must be able to adapt in presence of a dynamic context as mentioned above. Therefore, in this paper, we propose a dynamic maintenance grouping approach which can help to provide an optimal maintenance planning with maintenance constraints at lowest maintenance cost. The proposed maintenance grouping approach allows also the online update of the optimal maintenance planning in dynamic contexts.

\section{Dynamic maintenance grouping strategy}

This section is devoted to develop a dynamic maintenance grouping approach for maintenance optimization of multi-component systems with availability and repairmen constraints. The proposed dynamic grouping approach is basically developed from the rolling horizon approach and is divided into 4 phases: maintenance optimization at component level, tentative planning, grouping optimization, updating. The flowchart of the proposed approach is presented in Figure 2.

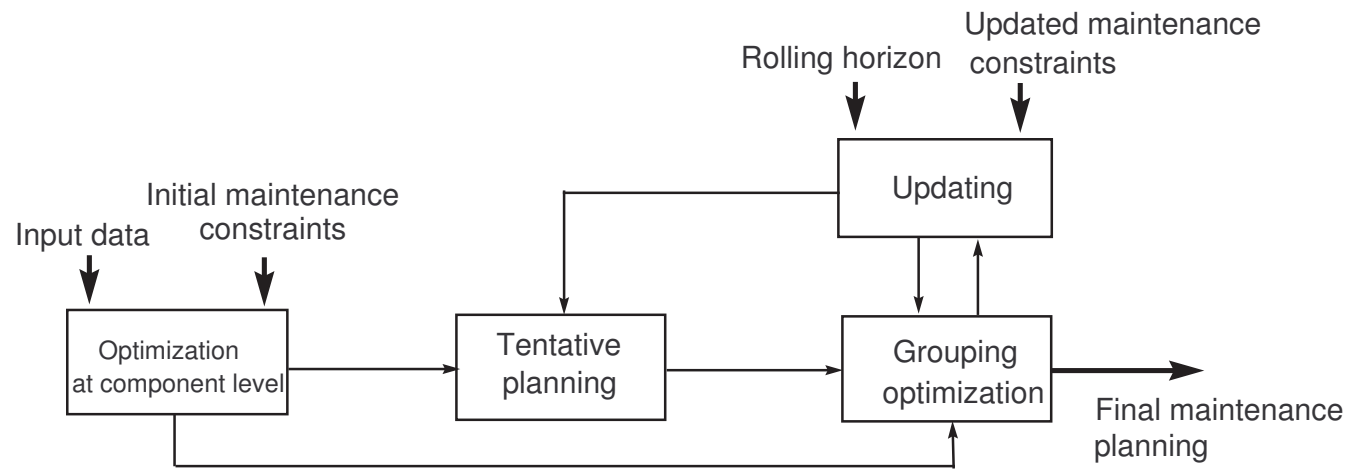

Figure 1: Maintenance grouping approach

\subsection{Phase 1: maintenance optimization at component level}

The objective of this phase is to find optimal preventive maintenance cycle for each component. An infinitehorizon maintenance model is used and all components are assumed to be isolated from each others, i.e., no interaction between components is considered at this stage.

For a better understanding of the proposed maintenance approach, Weibull distribution law is herein used as an example to describe the failure behaviors of the components. More precisely, the failure time of component $i(i=1, \ldots, n)$ is assumed to be described by a Weibull distribution with scale parameter $\lambda_{i}>0$, and shape parameter $\beta_{i}>1$. The corresponding failure rate is then:

$$
r_{i}(t)=\frac{\beta_{i}}{\lambda_{i}}\left(\frac{t}{\lambda_{i}}\right)^{\beta_{i}-1}
$$

Let $M_{i}(x)$ denote the expected deterioration cost for component $i$, i.e. the expected costs incurred in $x$ time units since the latest execution of activity $i$. According to the minimal repair policy, $M_{i}(x)$ can be 
expressed as:

$$
M_{i}(x)=C_{i}^{c} \cdot \int_{0}^{x} r_{i}(y) d y,
$$

where $r_{i}($.$) is the rate of occurrence of failure of component i$. From equations (3) and (4), we obtain:

$$
M_{i}(x)=C_{i}^{c} \cdot\left(\frac{x}{\lambda_{i}}\right)^{\beta_{i}}
$$

If component $i$ is preventively maintained at $x$, the expected cost within interval $\left[0, x+d_{i}\right]$ is:

$$
\Gamma_{i}(x)=C_{i}^{p}+M_{i}(x)=C_{i}^{p}+C_{i}^{c} \cdot\left(\frac{x}{\lambda_{i}}\right)^{\beta_{i}} .
$$

Using the renewal theory [23], the long-term average cost $\phi_{i}(x)$ when executing the preventive maintenance of component $i$ every $x$ time units amount is:

$$
\phi_{i}(x)=\frac{\Gamma_{i}(x)}{x}=\frac{C_{i}^{p}+C_{i}^{c} \cdot\left(\frac{x}{\lambda_{i}}\right)^{\beta_{i}}}{x} .
$$

This long-term average cost reaches the minimal value $\phi_{i}^{*}=\phi_{i}\left(x_{i}^{*}\right)$, where $x_{i}^{*}$ denotes the optimal interval length. From equation (7), one obtains:

$$
x_{i}^{*}=\lambda_{i} \sqrt[\beta_{i}]{\frac{C_{i}^{p}}{C_{i}^{c}\left(\beta_{i}-1\right)}},
$$

and the minimal long-term average cost:

$$
\phi_{i}^{*}=\phi_{i}\left(x_{i}^{*}\right)=\frac{C_{i}^{p} \beta_{i}}{x_{i}^{*}\left(\beta_{i}-1\right)} .
$$

This optimal interval length $x_{i}^{*}$ represents a nominal preventive maintenance period of component $i$ $(i=1, \ldots, N)$ and can be used to define tentative execution times which will be described in phase 2 . In that way, the minimum total maintenance cost per operating time unit of the system is calculated by:

$$
C_{I M}=\sum_{i=0}^{n} \phi_{i}^{*}
$$

\subsection{Phase 2: tentative planning}

The aim is to establish all tentative maintenance dates within a planning horion $\left[t_{\text {begin }}, t_{\text {end }}\right]$ using the nominal preventive maintenance period of components.

Based on the nominal preventive maintenance periods, the first tentative maintenance execution time of component $i(i=1, \ldots n)$ from the current date denoted $t_{\text {begin }}=t_{b}^{1}$ can be calculated by

$$
t_{i^{1}}=t_{\text {begin }}-t_{i}^{e}+x_{i}^{*}+d_{i}^{\Sigma},
$$

where $t_{i}^{e}$ is the operational time elapsed from the last preventive maintenance of component $i$ before $t_{\text {begin }}$, and $d_{i}^{\Sigma}$ is the cumulative maintenance durations before the execution of component $i . d_{i}^{\Sigma}$ is added since the system is stopped during maintenance. The illustration of $t_{i^{1}}$ is presented in Figure 2. 


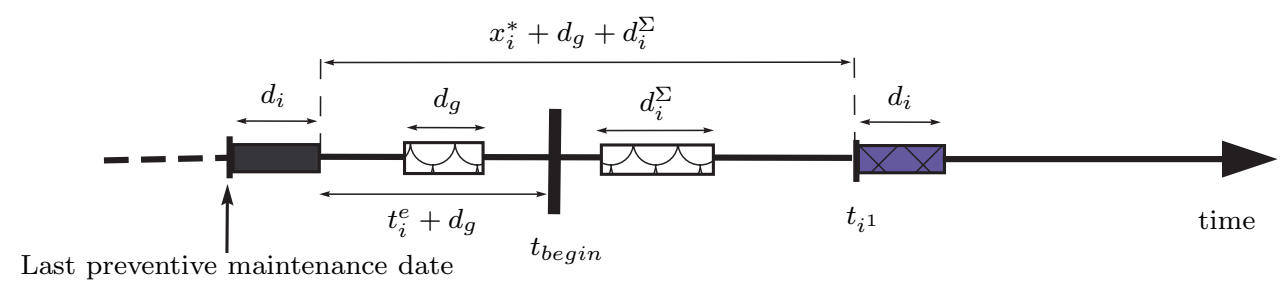

Figure 2: Illustration of $t_{i^{1}}$.

It is shown in $[7,30]$ that to ensure that all components are taken into account in the maintenance decision, the planning horizon should be chosen so that within this horizon interval each component is preventively performed at least one time. Therefore, $t_{e n d}=t_{e}^{U}$ if $t_{e}^{U}$ is larger than $\left(t_{j^{1}}+d_{j}\right)$ with $t_{j^{1}}=\max _{i=1: n} t_{i^{1}}$, otherwise $t_{\text {end }}=\left(t_{j^{1}}+d_{j}\right)$.

Since useful lifetime of components may be different, several components may be preventively maintained more than one time. Let $i^{j}$ be the $j$ th occurrence of maintenance activity $i$ (or component $i$ ) in the planning horizon, the tentative execution time of operation $i^{j}$, denoted $t_{i^{j}}(j \geq 2)$, depends on the executed time of operation $i^{j-1}$, denoted $t_{i^{j-1}}^{*}$, the cumulative maintenance durations $d_{i^{j-1}}^{\Sigma}$ from $t_{i^{j-1}}^{*}$, and the nominal periodicity $x_{i}^{*}$.

$$
t_{i^{j}}=t_{i^{j-1}}^{*}+d_{i^{j-1}}^{\Sigma}+x_{i}^{*}
$$

\subsection{Phase 3: maintenance grouping optimization at system level}

The main idea of this phase is to find an optimal maintenance planning which minimizes the total maintenance cost and copes with an availability level constraint under limited repairmen. The main idea is to find a grouping structure (or partition of all maintenance activities/operations within the planning horizon) for which at each maintenance time, several components are jointly replaced, so-called grouped maintenance action. In that way, each maintenance group is characterized by three parameters: maintenance operations, group execution date and group maintenance duration.

\subsubsection{Mathematical formulation}

Economic profit for a group Assume now that several different maintenance activities $i^{j}(i, j=$ $1,2, \ldots)$ are performed in a group $G^{k}$ (with $k=1,2, \ldots$ ). It should be noticed that operations $i^{j}$ and $i^{l}$ $(j \neq l)$ are identical operations since they are respectively the $j$ th and the $l$ th occurrence of maintenance activity $i$ for component $i$. They can not be in a same group.

The economic profit of the group $G^{k}$ can be divided into three parts as follows:

1. The penalty costs due to the changes of the individual optimal/tentative maintenance dates. Let $h_{i}\left(\Delta t_{i^{j}}\right)$ be the penalty cost when $i^{j}$ is actually executed at time $t_{i^{j}}^{*}=t_{i^{j}}+\Delta t_{i^{j}}$, with $\Delta t_{i^{j}}>-x_{i}^{*}$, instead of $t_{i^{j}}$. This change of execution time of activity $i^{j}$ leads to the following consequences, $[4,7,30]$ : 
- an increase in the expected costs over the jth renewal cycle given by $M_{i}\left(x_{i}^{*}+\Delta t_{i^{j}}\right)-M_{i}\left(x_{i}^{*}\right)$;

- a change cost due to the deferments of all future executions times after $t_{i^{j}}$ that are given by $\Delta t_{i^{j}} \cdot \phi_{i}^{*}$.

As a consequence, $h_{i}\left(\Delta t_{i^{j}}\right)$ can be written as:

$$
h_{i}\left(\Delta t_{i^{j}}\right)=C_{i}^{c} \cdot\left[\left(\frac{x_{i}^{*}+\Delta t_{i^{j}}}{\lambda_{i}}\right)^{\beta_{i}}-\left(\frac{x_{i}^{*}}{\lambda_{i}}\right)^{\beta_{i}}\right]-\Delta t_{i j} \frac{C_{i}^{p} \beta_{i}}{x_{i}^{*}\left(\beta_{i}-1\right)} .
$$

It should be noticed that another kind of penalty cost function can be found in [3]. Let $H_{G^{k}}(t)$ be the group penalty cost function at time $t$. The optimal execution time of the group $t_{G^{k}}$ can be found when the $H_{G^{k}}($.$) achieves its minimal value H_{G^{k}}^{*}$. That is:

$$
H_{G^{k}}^{*}=H_{G^{k}}\left(t_{G^{k}}\right)=\min _{t}\left(\sum_{i^{j} \in G^{k}} h_{i}\left(t-t_{i^{j}}\right)\right) .
$$

The optimal execution date for the group $t_{G^{k}}$ can be numerically determined.

2. The setup cost savings: according to [7,30] executing a group of several PM activities requires only one setup cost, the group $G^{k}$ yields a cost reduction:

$$
V_{1}\left(G^{k}\right)=\left(\operatorname{card}\left(G^{k}\right)-1\right) \cdot S
$$

where $\operatorname{card}\left(G^{k}\right)$ is the number of PM activities in group $G^{k}$. According to (15), it is clear that $V_{1}\left(G^{k}\right)$ depends on the number of PM activities in the group. It is important to note that other models of setup cost dependency can be found in [26].

3. An additional cost saving relying on the reduction of maintenance duration when several PM activities are simultaneously executed by $m$ repairmen.

$$
V_{2}\left(G^{k}, m\right)=\left(\sum_{i^{j} \in G^{k}} d_{i}-d_{G^{k}}(m)\right) C^{d}
$$

where $d_{G^{k}}(m)$ is the total duration of the group $G^{k}$. It is important to note that $d_{G^{k}}(m)$ depends on the duration of all group members and the number of repairmen $m$. If only one repairman is available, then $d_{G^{k}}(1)=\sum_{i^{j} \in G^{k}} d_{i}$, i.e., this additional cost saving is equal to 0 . For $m>1$, to find the minimum value of $d_{G^{k}}(m)$ an optimization algorithm, so called MULTIFIT algorithm, is employed. Its implementation is presented in Section 4.1.

From Equation (14), (15) and (16), the economic profits (saving cost) of group $G^{k}$, denoted $Q_{G^{k}}$, can be calculated as follows:

$$
Q_{G^{k}}=V_{1}\left(G^{k}\right)+V_{2}\left(G^{k}, m\right)-H_{G^{k}}^{*}
$$

Total economic profit In this step, we consider all the possible groups and to evaluate the total maintenance cost as a function of all the possible groups in the planning horizon $\left[t_{\text {begin }}, t_{\text {end }}\right]$. 
In fact, based on all different groups, a grouping structure, namely $G S$, can be identified. In fact, $G S$ is a collection of $l$ mutually exclusive groups $G^{1}, \ldots, G^{s}$ which cover all $N$ preventive maintenance activities in the planning horizon.

$$
G^{l} \cap G^{k}=\emptyset, \forall l \neq k \text { and } G^{1} \cup G^{2} \cup \ldots \cup G^{s}=\{1, \ldots, N\}
$$

In that way, the total economic profit of grouping structure $G S$, denoted $Q_{G S}$, is calculated as follows:

$$
Q_{G S}=\sum_{G^{k} \in G S} Q_{G^{k}}
$$

The total maintenance duration within a mission $i(i=1, \ldots, U)$ can be determined by:

$$
D^{i}=\sum_{t_{b}^{u} \leq t_{G^{k}}<t_{e}^{u}} d_{G^{k}}(m)
$$

According to the availability constraint presented in Section 2.2, a grouping structure is an optimal one, denoted $G S^{*}$, when the following conditions are verified:

$$
G S^{*}=\underset{G S}{\arg \max } Q_{G S}
$$

and,

$$
D^{i} \leq D_{0}^{i} \text { for } i=1, \ldots, U
$$

As a consequence, the minimum total maintenance cost per operating time unit within the considered planning horizon $\left[t_{\text {begin }}, t_{e n d}\right]$ is calculated by:

$$
C_{\text {grouping }}=C_{I M}-Q_{G S^{*}} /\left(t_{\text {end }}-t_{\text {begin }}-D_{G S^{*}}\right)
$$

\subsubsection{Finding optimal grouped maintenance planning under availability and limited repairmen constraints}

The finding of the optimal grouping structure becomes a NP-complete problem due to the impacts of limited maintenance duration, i.e. availability constraint in so far as we consider any combinations of all possible groups. Actually, the number of possible grouping structures increases very quickly with the increase of the number of PM activities. To find the optimal grouping structure, an exact method, which considers all possible grouping structures, would take too much computation time. It is shown in [29] that shows that exact methods are unusable if the number of PM activities is higher than 14.

It must be noticed that when only one repairman and no availability constraints are considered, a theorem of consecutive preventive maintenance activities is proposed in [30] in order to reduce the computational calculation time. The main idea of this theorem is that given several consecutive PM activities $i, j, k$ with $t_{i}<t_{j}<t_{k}\left(t_{i}\right.$ is the tentative maintenance date of PM activity $\left.i\right)$, if PM activities $i$ et $k$ are grouped in a group then the PM activity $j$ must be in this group. Thanks to the proposed theorem, the number of possible groups can be dramatically reduced. In doing that, dynamic programming has been successfully 
used as an efficient optimization technique to find the optimal grouping planning in many works, see for instance $[3,7,30]$. However, the proposed theorem is no longer applicable in presence of repairmen and availability (or limited maintenance duration) constraint. As an example, given 4 PM activities $i, j, k, h$ with tentative maintenance dates $t_{i}<t_{j}<t_{k}<t_{h}$ (these PM activities are consecutive) and its maintenance duration $d_{i}=d_{k}=1$ and $d_{j}=d_{h}=3$. It is assumed that only two repairmen are available for executing maintenance and the total maintenance duration is limited to 4. According to the theorem, to archive the maintenance duration constraint, only one solution is the grouping of four maintenance activities. However, it is easy to see that the second solution is possible: $i, k$ are grouped in the first group and $j, h$ are grouped in the second one. If $t_{i}$ and $t_{h}$ are so far, the second solution may provide more maintenance cost saving than the first one provided by the theorem of consecutive preventive maintenance activities.

To face this issue, an other efficient optimization technique is needed. Generic Algorithms (GA) have been considered as a relevant optimization approach in the maintenance optimization framework, see for instance $[13,27,5,17,28]$. In that way, GA is used and developed to find the grouped maintenance planning in this work. Detailed description on the implementation of GA algorithm in the specific context of the present work will be discussed in Section 4.

\subsection{Phase 4: updating of the maintenance planning}

The current optimal maintenance planning needs to be updated according to one of the two following reasons:

1. in presence of new maintenance constraints. After to the previous phase, we have an optimal grouped maintenance planning within the finite planning horizon $\left[t_{\text {begin }}, t_{\text {end }}\right]$. However, with time maintenance constraints, by which the current planning can be directly impacted, may be changed, e.g., several repairmen may become unavailable during given time periods; the average availability level required for given missions may be changed. In that way, the current maintenance planning may become no longer an optimal or even unusable one. A new maintenance planning is needed. To integrate this kind of dynamic context, we simply go back to phase "grouping optimization". The illustration of the updating process of the grouped maintenance planning in presence of new maintenance constraint is shown in Figure 3.

It should be noticed that updating of maintenance planning may be needed in presence of other dynamic contexts such as maintenance opportunities [7], spares parts replenishment, change of production planning, etc [29].

2. at the end of the current planning horizon. A new maintenance planning for the next horizon is needed. New horizon can be constructed based on new required missions' interval with new maintenance constraints (availability and/or repairmen constraints). For this purpose, the rolling horizon procedure is used by returning to phase 2 of the optimization scheme to redefine all preventive maintenance activities in the new tentative planning horizon and so on. 


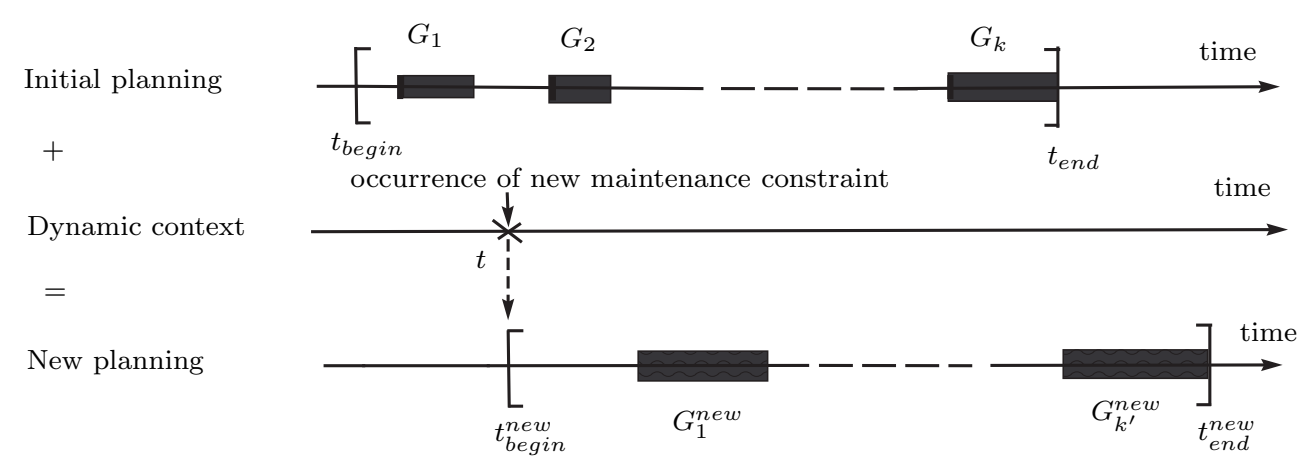

Figure 3: Updating process of the grouped maintenance planning in presence of new maintenance constraint.

\section{Implementation of optimization algorithms}

This section is devoted to present how the two mentioned optimization algorithms (MULTIFIT and GA algorithm) can be implemented and integrated in the proposed maintenance grouping approach.

\subsection{MULTIFIT algorithm}

The main idea of the implementation of MULTIFIT algorithm is to schedule optimally a group of maintenance activities for a limited maintenance teams in order to minimize the total maintenance duration. It should be noticed that MULTIFIT algorithm is the most popular method for the problem of scheduling a set of independent jobs on a limited identical machines with the objective of minimizing the total finishing time.

Without loss of generality, consider now a group consisting of $k$ maintenance activities. To perform the maintenance of the group, only $m(m \leq k)$ repairmen are available.

Step 0 It is assumed that $k$ maintenance activities are renumbered by increasing order according to their decreasing duration, i.e. $d_{1} \geq d_{2} \geq \ldots \geq d_{k}$. Next, let $D_{G^{k}}^{u p}=\max \left(d_{1}, 2 \sum_{i=1}^{k} d_{i} / m\right)$ and $D_{G^{k}}^{\text {low }}=$ $\max \left(d_{1}, \sum_{i=1}^{k} d_{i} / m\right)$. And finally, set $w=0$.

Step 1 Set $D_{G^{k}}=\frac{1}{2}\left(D_{G^{k}}^{u p}+D_{G^{k}}^{l o w}\right)$ and $w=w+1$.

Step 2 Assign maintenance activities to repairmen with limited time $D_{G^{k}}$ according to First Fit Decreasing method (FFD), [12]. The FFD method assigns the PM activity in succession to the lowest indexed repairmen which can complete the PM activity within limited time $D_{G^{k}}$.

Step 3 If all activities can be assigned to $m$ repairmen, then set $D_{G^{k}}^{u p}=D_{G^{k}}$ and go to step 4 , otherwise set $D_{G^{k}}^{l o w}=D_{G^{k}}$ and go to step 4 .

Step 4 If $w=w_{\max }$ then stop, otherwise go to step 1 .

It is shown in [6] that the worst-case performance ratio is:

$$
\alpha=\frac{D_{G^{k}}^{\text {found optimum }}}{D_{G^{k}}^{\text {real optimum }}}=\frac{13}{11}+2^{-w_{\max }}
$$


The iterations number can be fixed in advance, as recommended in $[6], w_{\max }=7$. In that way, after 7 iterations we obtain an optimal value of $D_{G^{k}}$.

As an example, assume that only two maintenance teams are available for executing a group of 8 maintenance activities with $d_{1}=6, d_{2}=5, d_{3}=5, d_{4}=5, d_{5}=4, d_{6}=3, d_{7}=2$ and $d_{8}=1$. The optimal scheduling provided by MULTIFIT algorithm is sketched in Figure4.

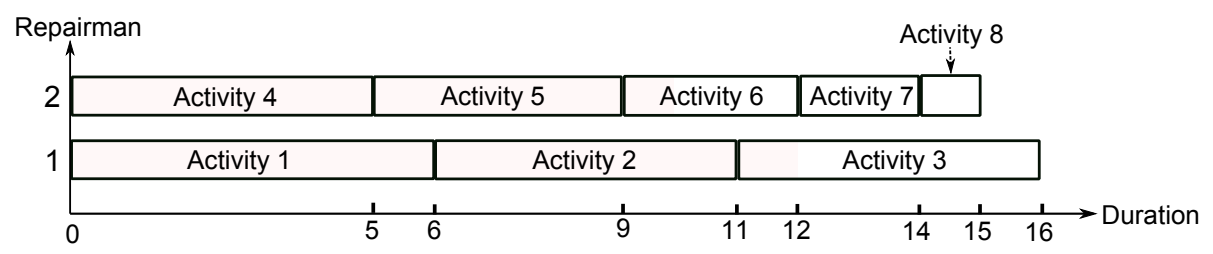

Figure 4: Optimal scheduling of 8 maintenance activities under 2 repairmen

The minimum maintenance duration of the group is 16 time units.

\subsection{Genetic algorithm}

The Genetic Algorithm has been recognized as a general search strategy which is often useful for solving combinatorial problems, see [10]. Recently, GA has been widely studied, experimented and applied in many fields in engineering worlds. A GA starts by creating an initial population of solutions. Each solution is next evaluated using an objective function. During each iteration step, genetic operations (crossover and mutation operations) are applied in order to search potential better solutions. Repair procedures are applied each time when an infeasible solution occurs to repair this solution, and to put it back into the search space. The GA structure is in presented in Figure 5.

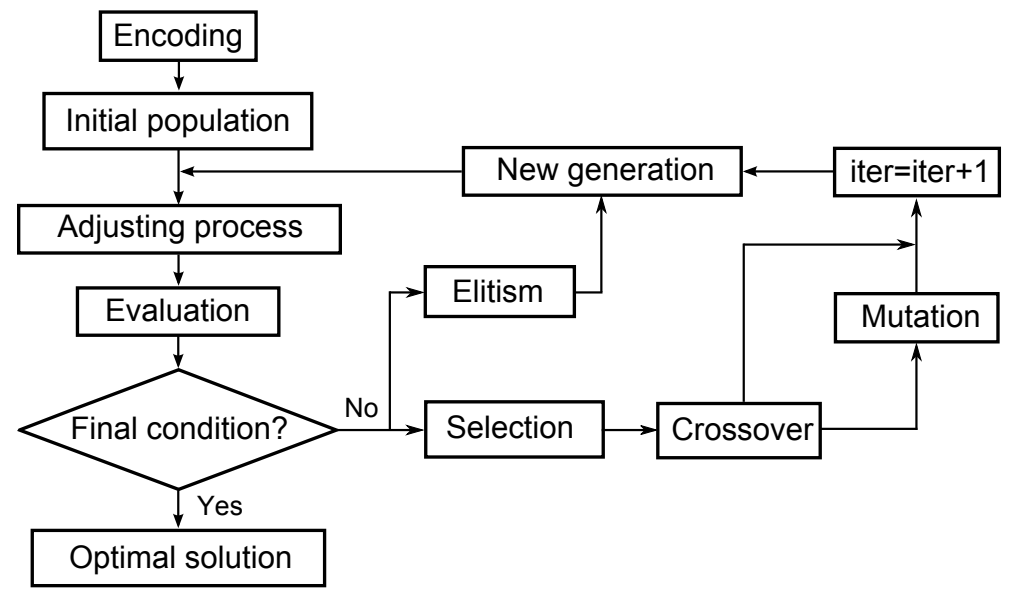

Figure 5: Structure of GA

\subsubsection{Encoding}

Each solution is represented by an array, namely $X$, with $N$ elements which correspond to $N$ PM activities. If maintenance activity $i$ is in group $j$ then $X(i)=j$. Here, $X$ corresponds to a grouping structure. 
Example: considering 7 preventive activities. A feasible solution containing 3 groups $G_{1}=\left\{1^{1}, 2^{1}, 4^{1}\right\}$, $G_{2}=\left\{3^{1}, 5^{2}\right\}, G_{3}=\left\{2^{2}, 5^{1}\right\}$ is represented by array $X$ as follows:

\begin{tabular}{|c|c|c|c|c|c|c|c|}
\hline$X=$ & 1 & 1 & 2 & 1 & 3 & 3 & 2 \\
\hline
\end{tabular}

Figure 6: An example of solution encoding

\subsubsection{Generation of initial population}

GA makes randomly an initial population of solutions. If there are too few solutions in the population, GA have a few possibilities to perform crossover and only a small part of search space is explored. On the other hand, if there are too many solutions, GA slows down. The population size is usually chosen between 60 and 100 solutions. To generate an initial solution, the number of groups in the solution is randomly chosen between 1 and $n-1$. Next, all maintenance activities are randomly put into the chosen groups.

\subsubsection{Adjusting process}

Consider an infeasible solution, in which the availability constraints are not satisfied at some intervals.

$$
D^{u}=\sum_{G^{k} \in u} d_{G^{k}}(m)=\sum_{t_{b}^{u} \leq t_{G^{k}}<t_{e}^{u}} d_{G^{k}}(m)>D_{0}^{u}
$$

where, $D^{u}$ is the total maintenance duration of the mission $u$ within $\left[t_{b}^{u}, t_{e}^{u}\right]$ and $D_{0}^{u}$ is the maximal total maintenance durations allowed in this mission.

To adjust this infeasible solution, we propose here two following ways which allow reducing the total maintenance durations of mission $u$ :

1. Increase the number of repairmen: Here, we try to increase the number of repairmen to reduce the maintenance duration of groups in mission $u$. To this end, the following steps are proposed:

- Step 1: $m=m+1$, where, $m$ is the number of repairmen.

- Step 2: recalculate the total maintenance durations of groups of mission $u, D^{u}$, by reusing MULTIFIT algorithm in section 4.1 with the new value of $m$.

- Step 3: return to step 1 until constraint (24) is satisfied.

Note well that the adjusting process can reduce the total maintenance durations $D^{u}$ to $D_{\text {min }}^{u}$ which is defined as the following:

$$
D_{\min }^{u}=\sum_{G^{k} \in u} \min _{i \in G^{k}} d_{i}
$$

As consequence, when $D_{0}^{u}<D_{\min }^{u}$ or when the number of repairmen does not change, the adjusting process does not work. For this reason, the second strategy is proposed.

2. Postpone some PM activities to other intervals: Herein, we try to postpone some PM activities in the interval $\left[t_{b}^{u}, t_{e}^{u}\right]$ to other intervals. This procedure is described as follows: 
- Step 1: randomly choose one maintenance activity which is planned to maintain in the interval $\left[t_{b}^{u}, t_{e}^{u}\right]$

- Step 2: move the chosen activity to other intervals;

- Step 3: return to step 1 until constraint (24) is satisfied.

\subsubsection{Evaluation}

Each solution is evaluated by its fitness function. To calculate the fitness value of solution $X$, denoted $f(X)$, the grouping structure $G S$ which corresponds to array $X$ is firstly identified by the following decoding process: if $X(i)=j$ then $i$ is put into group $j$. After that, the fitness function is defined as follows:

$$
f(X)=Q_{G S}=\sum_{G^{k} \in G S} Q_{G^{k}}
$$

where, $Q_{G^{k}}$ is group savings of $G^{k}$ which is determined by equation (17).

\subsubsection{Elitism}

In this step, the two best solutions are directly copied to the next generation in order to protect the best solutions from the high level of disruption .

\subsubsection{Selection}

The "linear ranking selection" proposed in [2] is used to select pairs of parent solutions for the Crossover phase. Firstly, parent solutions are sorted according to their fitness values in ascending order, and the population is categorized into $s$ groups. Next, a parent solution is randomly chosen from these $s$ groups with $s$ groups probabilities $p_{1} \leq p_{2} \leq \ldots \leq p_{s}\left(\sum_{i=1}^{s} p_{i}=1\right)$ respectively. Thus, the fitter a solution is, the more chance it has to be chosen for a parent in the next generation. This combinatorial grouping was found most effective. In this work, 60 parent solutions are divided into 5 groups $(s=5)$ of 12 solutions in which the first group is composed by last 12 worst solutions and so on. The groups selection probability are $5 \%$, $10 \%, 15 \%, 25 \%$ and $45 \%$.

\subsubsection{Crossover}

Crossover probability: each pair of selected solutions is now randomly selected for crossover operator with a crossover probability that is introduced to leave some part of the population survive to the next generation. The self-adaptive of crossover probability $P_{c}$ proposed in [16] is used and determined:

$$
P_{c}= \begin{cases}P_{c}^{\max }-\frac{\left(P_{c}^{\max }-P_{c}^{\min }\right) \cdot\left(f_{c}-f_{a v g}\right)}{f_{\max }-f_{\text {avg }}} & \text { if } f_{c} \geq f_{\text {avg }} \\ P_{c}^{\max } & \text { if } f_{c}<f_{\text {avg }}\end{cases}
$$

where, 
- $P_{c}^{\max }$ and $P_{c}^{\min }$ denote the lower bound and upper bound of crossover probability respectively: $P_{c}^{\min }=$ $0.60 ; P_{c}^{\max }=0.95$

- $f_{\text {max }}$ and $f_{a v g}$ denote the maximal fitness and the average fitness of all solutions in the population respectively;

- $f_{c}$ denotes the higher fitness of two parent solutions.

Crossover operator: the objective is to combine selected solutions to generate next better generation solutions by preserving their characteristics. 2-points crossover [22] is applied in this algorithm. First, two PM activities are randomly chosen as the crossover points. And then, the elements between these points of the selected parent solutions are exchanged to create new solutions.

\subsubsection{Mutation}

Mutation probability: mutation is made to prevent falling GA into local extreme, but it should not occur very often, because then GA will in fact change to random search. Therefore, the self-adaptive of mutation probability $P_{m}$ proposed in [16] is used.

$$
P_{m}= \begin{cases}P_{m}^{\max }-\frac{\left(P_{m}^{\max }-P_{m}^{\min }\right) \cdot\left(f_{\max }-f_{m}\right)}{f_{\max }-f_{\text {avg }}} & \text { if } f_{m} \geq f_{\text {avg }} \\ P_{m}^{\max } & \text { if } f_{m}<f_{\text {avg }}\end{cases}
$$

where,

- $P_{m}^{\max }$ and $P_{m}^{\min }$ denote the lower bound and upper bound of mutation probability respectively: $P_{m}^{\min }=$ $0.01, P_{m}^{\max }=0.10$;

- $f_{\max }$ and $f_{\text {avg }}$ denote the maximal fitness and the average fitness of all solutions in the population respectively;

- $f_{m}$ denotes the fitness of the mutation solution.

Mutation operator: for each selected solution, a random maintenance activity in a group is next moved to another group in order to generate a new solution.

\subsubsection{Final condition}

Final condition is introduced to stop the algorithm process. Herein, the algorithm process is stopped when the iteration number reaches its limited value or when after a given number of consecutive iterations without improving the fitness of the best solution.

\subsubsection{Optimal solution}

The optimal solution with highest fitness value is searched among the last generation solutions. 


\section{Numerical example}

The purpose of this section is to show how the proposed grouping strategy can be used in preventive maintenance optimization with availability constraint under limited maintenance teams through a series structure system consisting of 20 components. When a component fails, it is immediately maintained according to a minimal-repair policy. A corrective maintenance restores the failed component to its "as bad as old" state. The corrective maintenance duration is assumed to be negligible. To avoid the failure occurrence, each component is preventively replaced with non-negligible maintenance duration. In this study, it is assumed that the failure behavior of component $i(i=1, \ldots, 20)$ is described by a Weibull distribution with scale parameter $\lambda_{i}>0$, and shape parameter $\beta_{i}>1$.

Table 1 reports the life time parameters and maintenance costs for the 20 components. It should be noticed that, in this study, all parameters are given in arbitrary units, either arbitrary time unit (atu) or arbitrary cost unit (acu), e.g., in Table $1 \lambda_{i}, d_{i}, t_{i}^{e}$ are given in atu and $c_{i}^{p}, C_{i}^{c}$ in acu. For setup cost and unavailability cost rate, we take $S=10$ (acu) and $C^{d}=5$ (acu/atu) respectively.

\begin{tabular}{ccccccc|ccccccc}
\hline Component & $\lambda_{i}$ & $\beta_{i}$ & $c_{i}^{p}$ & $C_{i}^{c}$ & $d_{i}$ & $t_{i}^{e}$ & Component & $\lambda_{i}$ & $\beta_{i}$ & $c_{i}^{p}$ & $C_{i}^{c}$ & $d_{i}$ & $t_{i}^{e}$ \\
\hline 1 & 237 & 1.5155 & 266 & 79 & 1 & 847.7 & 11 & 209 & 1.8171 & 380 & 52 & 2 & 461.9 \\
2 & 255 & 1.3981 & 347 & 67 & 2 & 1614.1 & 12 & 297 & 1.5439 & 376 & 56 & 5 & 1327.3 \\
3 & 335 & 1.6527 & 322 & 94 & 6 & 903.6 & 13 & 326 & 2.0178 & 279 & 80 & 5 & 326.4 \\
4 & 291 & 1.8663 & 362 & 85 & 2 & 602.1 & 14 & 236 & 1.5127 & 249 & 59 & 1 & 663.3 \\
5 & 186 & 1.3280 & 500 & 59 & 3 & 2122.1 & 15 & 278 & 1.2336 & 221 & 66 & 5 & 2357.4 \\
6 & 263 & 2.0819 & 401 & 60 & 4 & 466.9 & 16 & 169 & 1.7985 & 342 & 85 & 2 & 69.7 \\
7 & 260 & 2.1427 & 326 & 100 & 3 & 247.0 & 17 & 281 & 1.6067 & 446 & 86 & 6 & 750.0 \\
8 & 243 & 2.1816 & 247 & 43 & 5 & 324.1 & 18 & 257 & 1.5251 & 232 & 81 & 4 & 405.6 \\
9 & 226 & 1.3909 & 329 & 75 & 4 & 1144.7 & 19 & 235 & 1.2908 & 280 & 58 & 3 & 1726.6 \\
10 & 268 & 1.4262 & 316 & 80 & 3 & 1096.9 & 20 & 239 & 1.7271 & 338 & 24 & 5 & 873.4 \\
\hline
\end{tabular}

Table 1: Data of a 20-component system.

By assuming that all components are individually maintained, nominal maintenance periodicity $x_{i}^{*}$, minimum maintenance cost rate $\phi_{i}^{*}$ and the next preventive replacement date $t_{i^{1}}($ with $i=1, \ldots, 20)$ are calculated by substitution of the input data in Equations (8) and (11). The results are given in Table 2.

According to these results, if preventive maintenance of components are separately performed the minimum total maintenance cost per operating time unit is then:

$$
C_{I M}=\sum_{i=1}^{20} \phi_{i}^{*}=19.75 .
$$

In this case, the planning horizon starts at the current date equal to $0\left(t_{\text {begin }}=0\right)$ and the ending horizon date corresponds to $t_{20^{1}}+d_{20}=605\left(t_{\text {end }}=605\right)$. The total maintenance duration is $\sum_{i=1}^{20} d_{i}=71$ and the average availability of the system when all components are separately maintained is then 0.8826 . The total 


\begin{tabular}{cccc||cccc}
\hline Component & $x_{i}^{*}$ & $\phi_{i}^{*}$ & $t_{i^{1}}$ & Component & $x_{i}^{*}$ & $\phi_{i}^{*}$ & $t_{i^{1}}$ \\
\hline 1 & 847.7 & 0.9745 & 0 & 11 & 717.9 & 1.2391 & 289 \\
2 & 1663.1 & 0.7750 & 50 & 12 & 1602.3 & 0.7281 & 310 \\
3 & 980.6 & 0.9348 & 80 & 13 & 636.4 & 0.9782 & 350 \\
4 & 703.1 & 1.1705 & 110 & 14 & 988.3 & 0.7881 & 370 \\
5 & 2231.1 & 0.9519 & 120 & 15 & 2711.4 & 0.4986 & 400 \\
6 & 652.9 & 1.2703 & 200 & 16 & 428.7 & 1.9021 & 410 \\
7 & 439.0 & 1.4994 & 210 & 17 & 1127.0 & 1.1421 & 430 \\
8 & 533.1 & 0.9767 & 230 & 18 & 846.6 & 0.8989 & 500 \\
9 & 1368.7 & 0.9333 & 250 & 19 & 2213.6 & 0.6116 & 550 \\
10 & 1364.9 & 0.8472 & 280 & 20 & 1407.4 & 0.6295 & 600 \\
\hline
\end{tabular}

Table 2: Values of $x_{i}^{*}, \phi_{i}^{*}$, and $t_{i^{1}}$.

maintenance cost within the planning horizon is:

$$
T C_{I M}=C_{I M} \cdot(605-71)=10546.5
$$

To illustrate the use and the advantages of the proposed grouping strategy, the following studies are investigated:

- Maintenance planning \& grouping without availability constraints and unlimited repairmen;

- Impacts of limited repairmen on the maintenance planning \& grouping and on the system availability;

- Impacts of availability constraint on the maintenance planning \& grouping;

- Maintenance planning \& grouping with multi-availability level constraint;

- Maintenance planning \& grouping with both availability level and repairmen constraint.

\subsection{Maintenance planning \& grouping without availability constraints and unlimited repairmen}

It is assumed that the system has to serve only one mission during $[0,605]$ for which no availability contraint is considered. The maintenance teams are assumed to be unlimited for maintenance execution. In doing so, by applying the proposed grouping strategy, the optimal grouping solution is reported in Table 3. Two optimal groups $G^{1}=\{1, \ldots, 11\}$ and $G^{2}=\{12, \ldots, 20\}$ are found.

\begin{tabular}{ccccc}
\hline Group components & Optimal date $t_{G}$ & Duration $d_{G}$ & Profit $Q_{G}$ & Total profit $Q_{G S^{*}}$ \\
\hline$\{1, \ldots, 11\}$ & 173.3 & 6 & 219.6593 & \multirow{2}{*}{438.9792} \\
$\{12, \ldots, 20\}$ & 364.8 & 6 & 219.3199 & \\
\hline
\end{tabular}

Table 3: Grouping without availability constraint and unlimited repairmen number

As an example, Figure 7 shows the optimal scheduling of group $G^{2}$ on 7 maintenance teams. It is clear that the minimum maintenance of the group $G^{2}$ is 6 time units. 


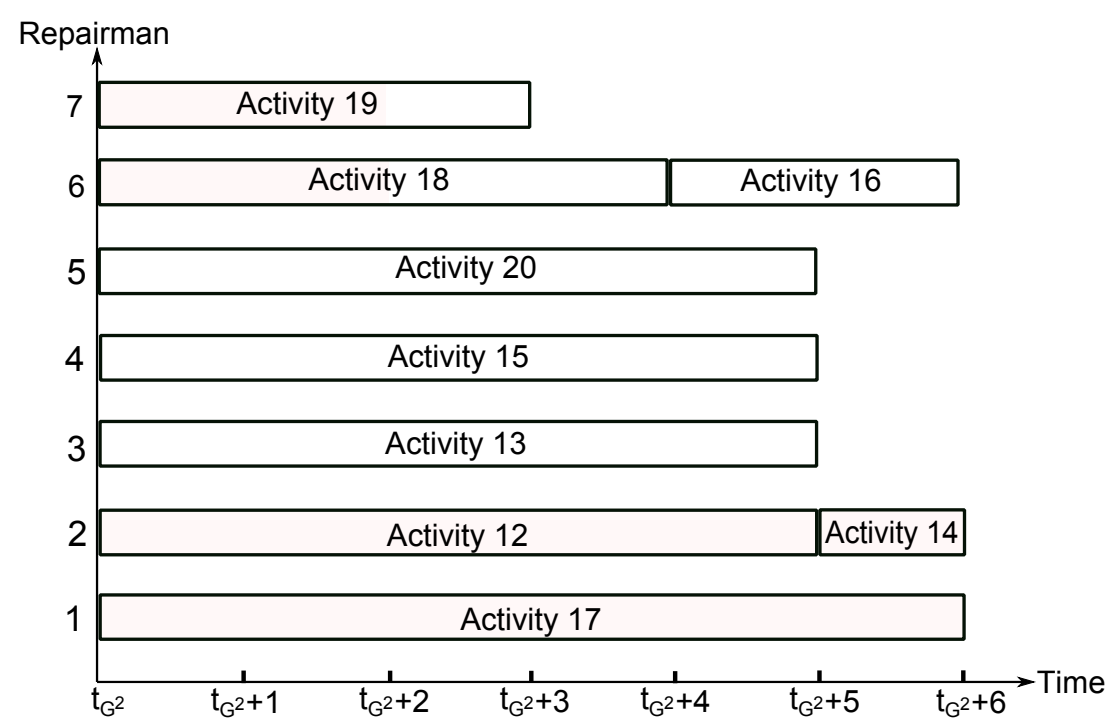

Figure 7: Optimal scheduling of of group $G^{2}=\{12, \ldots, 20\}$ on 7 repairmen

The obtained results in Table 3 show that the total maintenance cost saving is $Q_{G S^{*}}=438.9792$ which is about $3.75 \%$ of $T C_{I M}$. Moreover, it is important to note that the total maintenance duration is dramatically reduced, $D_{G S^{*}}=12$. As a consequence, the average availability of the system within the planning horion increases significantly and equals to 0.9802. In addition, according to the proposed maintenance approach, only 7 repairmen are needed for executing the optimal grouped maintenance planning. This interesting result can help maintenance manager to schedule more optimally repairmen tasks. Of course if the number repairmen is limited, i.e. lower than 7 , the grouped maintenance planning above is no longer an optimal one. To face this problem, the impacts of the limited repairmen on the maintenance planning and on the system availability are investigated and presented in the next subsection.

\subsection{Impacts of limited repairmen on the maintenance planning \& group- ing and on the system availability}

To study the impacts of limited repairmen, the number of repairmen $m$ is herein varied from 1 to 10 . For each value of $m$, by using the proposed maintenance grouping approach, an optimal maintenance planning is provided. It is assumed that an increase of repairmen do not lead to any additional cost. The results are reported in Table 4. It is found that under limited repairmen constraint, the theorem of consecutive preventive maintenance activities is no longer applicable, see for example the cases with $m=3,4,5$. 


\begin{tabular}{|c|c|c|c|c|}
\hline$m$ & Optimal solution & $t_{G}$ & $d_{G}$ & $Q_{G S^{*}}$ \\
\hline \multirow{3}{*}{1} & $G 1=\{1, \ldots, 5\}$ & 71.3 & 14 & \multirow{3}{*}{154.5121} \\
\hline & $G 2=\{6, \ldots, 12\}$ & 218.9 & 26 & \\
\hline & $G 3=\{13, \ldots, 20\}$ & 401.7 & 31 & \\
\hline \multirow{3}{*}{2} & $G 1=\{1, . ., 5\}$ & 71.3 & 7 & \multirow{3}{*}{329.5121} \\
\hline & $G 2=\{6, \ldots, 12\}$ & 211.9 & 13 & \\
\hline & $G 3=\{13, \ldots, 20\}$ & 381.7 & 16 & \\
\hline \multirow{3}{*}{3} & $G 1=\{1, \ldots, 5,9\}$ & 83.9 & 6 & \multirow{3}{*}{386.3262} \\
\hline & $G 2=\{6,7,8,10,11\}$ & 208.8 & 6 & \\
\hline & $G 3=\{12, \ldots, 20\}$ & 370.8 & 12 & \\
\hline \multirow{3}{*}{4} & $G 1=\{1, \ldots, 5,9,15\}$ & 87.4 & 6 & \multirow{3}{*}{410.1913} \\
\hline & $G 2=\{6,7,8,10,11,12\}$ & 210.4 & 6 & \\
\hline & $G 3=\{13,14,16, \ldots, 20\}$ & 373.8 & 7 & \\
\hline \multirow{3}{*}{5} & $G 1=\{1,2,4\}$ & 68.9 & 2 & \multirow{3}{*}{423.4065} \\
\hline & $G 2=\{3,5, \ldots, 12,15\}$ & 199.0 & 8 & \\
\hline & $G 3=\{13,14,16, \ldots, 20\}$ & 371.8 & 6 & \\
\hline \multirow{2}{*}{6} & $G 1=\{1, \ldots, 11\}$ & 173.3 & 6 & \multirow{2}{*}{433.9792} \\
\hline & $G 2=\{12, \ldots, 20\}$ & 364.8 & 7 & \\
\hline \multirow{2}{*}{$\geq 7$} & $G 1=\{1, \ldots, 11\}$ & 173.3 & 6 & \multirow{2}{*}{438.9792} \\
\hline & $G 2=\{12, \ldots, 20\}$ & 364.8 & 6 & \\
\hline
\end{tabular}

Table 4: Grouped maintenance planning under limited repairmen

The impacts of the number of repairmen on the maintenance cost and the average availability are sketched in Figure 8.
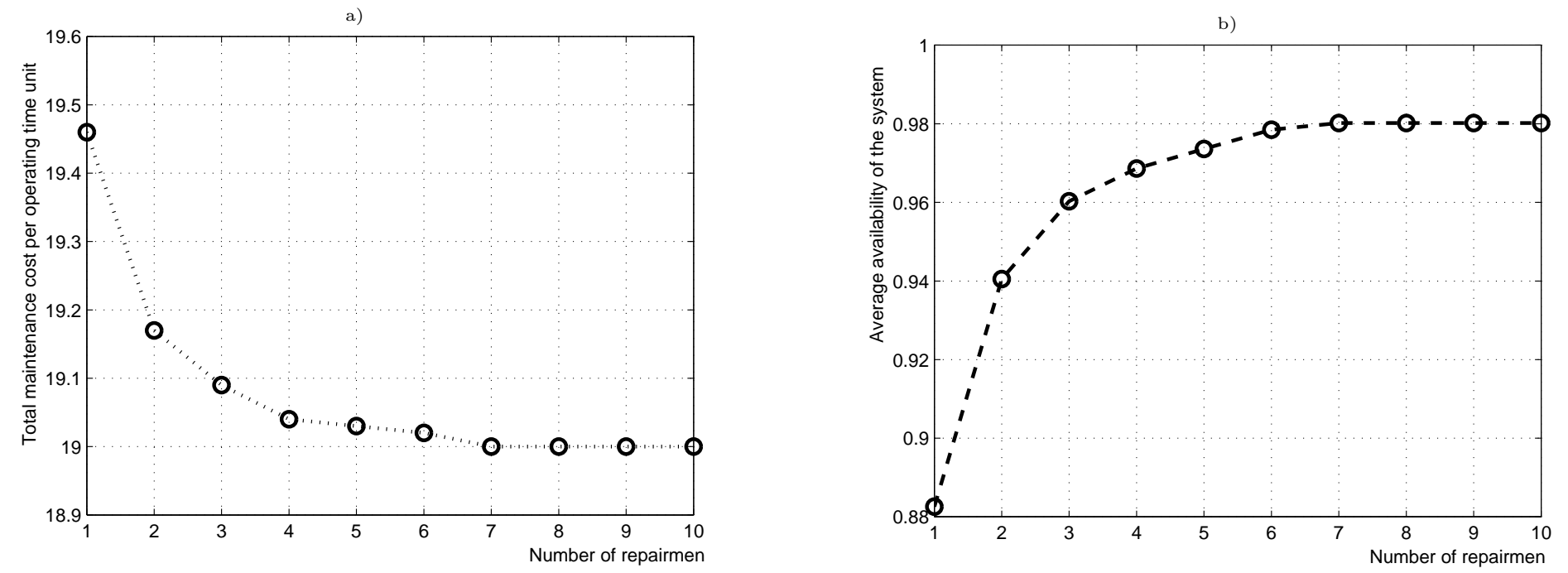

Figure 8: Impact of the number of repairmen on (a) the total maintenance cost rate and (b) the average availability of the system

The obtained results show that, when the number of repairmen is lower than $7(m \leq 7)$, the maintenance 
benefit (saving cost) and the average availability of the system increase significantly with the increasing of the number of repairmen. This can be explained by the fact that the maintenance duration can be reduced by increasing the number of repairmen. It is important to note that a reduction of maintenance duration leads not only to an increase of the maintenance benefit, i.e. a reduction of total maintenance cost, but also to an increase of the average availability of the system.

Moreover, it is interesting to note that when the number of repairmen is high enough (herein $m \geq 7$ ), the optimal maintenance planning remains unchanged, i.e., an increase of the number of repairmen impacts no longer the maintenance cost and the average availability of the system.

\subsection{Impacts of availability constraint on the maintenance planning \& grouping}

In this section, only one mission is considered within the planning horizon [0 605]. To investigate the impact of the availability constraint on the maintenance planning, different levels of availability are considered. In fact, the required average availability level $A_{0}^{1}$ is varied from 1 to 0.9802 . It should be noticed that 0.9802 is the average availability level provided by the proposed grouping strategy when the availability constraint is released. This means also that when the required average availability level is not higher than 0.9802 , the proposed maintenance approach provides an optimal maintenance planning for which the average availability of the system equals to 0.9802 . In that way, the obtained results are reported in Table 5 .

\begin{tabular}{|c|c|c|c|c|}
\hline Required average availability level $A_{0}^{1}$ & Optimal solution & $t_{G}$ & $d_{G}$ & $Q_{G S^{*}}$ \\
\hline 1 & $G 1=\{1, \ldots, 20\}$ & 605 & 0 & -785.200 \\
\hline 0.995 & $G 1=\{1, \ldots, 20\}$ & 602 & 3 & -764.743 \\
\hline 0.9901 & $G 1=\{1, \ldots, 20\}$ & 241.5 & 6 & 396.7430 \\
\hline \multirow{2}{*}{0.9884} & $G 1=\{1\}$ & 0 & 1 & \multirow{2}{*}{398.7568} \\
\hline \multirow{2}{*}{0.9868} & $G 2=\{2, \ldots, 20\}$ & 249.1 & 6 & \\
\hline \multirow{2}{*}{0.9835} & $G 1=\{1,2,4\}$ & 68.9 & 2 & \multirow{2}{*}{413.7074} \\
& $G 2=\{3,5, \ldots, 20\}$ & 263.8 & 6 & \\
\hline \multirow{2}{*}{0.9818} & $G 1=\{1,2,4\}$ & 68.9 & 2 & \\
& $G 2=\{3,5, \ldots, 13,15,17, \ldots, 20\}$ & 237.9 & 6 & \multirow{2}{*}{419.5710} \\
& $G 3=\{14,16\}$ & 362.6 & 2 & \\
\hline \multirow{2}{*}{0.9802} & $G 1=\{1, \ldots, 11,17\}$ & 182.6 & 6 & \multirow{2}{*}{432.0986} \\
\hline & $G 2=\{12, \ldots, 16,18, \ldots, 20\}$ & 363.5 & 5 & \\
\hline & $G 1=\{1, \ldots, 11\}$ & 173.3 & 6 & \multirow{2}{*}{438.9792} \\
\hline
\end{tabular}

Table 5: Maintenance planning with different levels of average availability

Figure 9.a shows the sensitivity of the total maintenance cost per operating time unit to the required average availability level. It is clear that, when the required availability level is not lower than 0.9802 , the higher the required average availability level the higher maintenance cost is. Especially, when no preventive 
maintenance is allowed within the considered interval (the required average availability level equals to 1) the maintenance cost increases dramatically. It is important to note that a required average availability level can be reached when the number of repairmen is high enough. In fact, Figure 9.b illustrates the relationship between the required average availability level and the optimal repairmen number for which the corresponding maintenance cost is the lowest. When the average availability level is not higher than 0.9818, only 7 repairmen are needed to execute the preventive maintenance operations. However, when the average availability level is not lower than 0.9884 , the number of required repairmen increases and the optimal one is 13 .
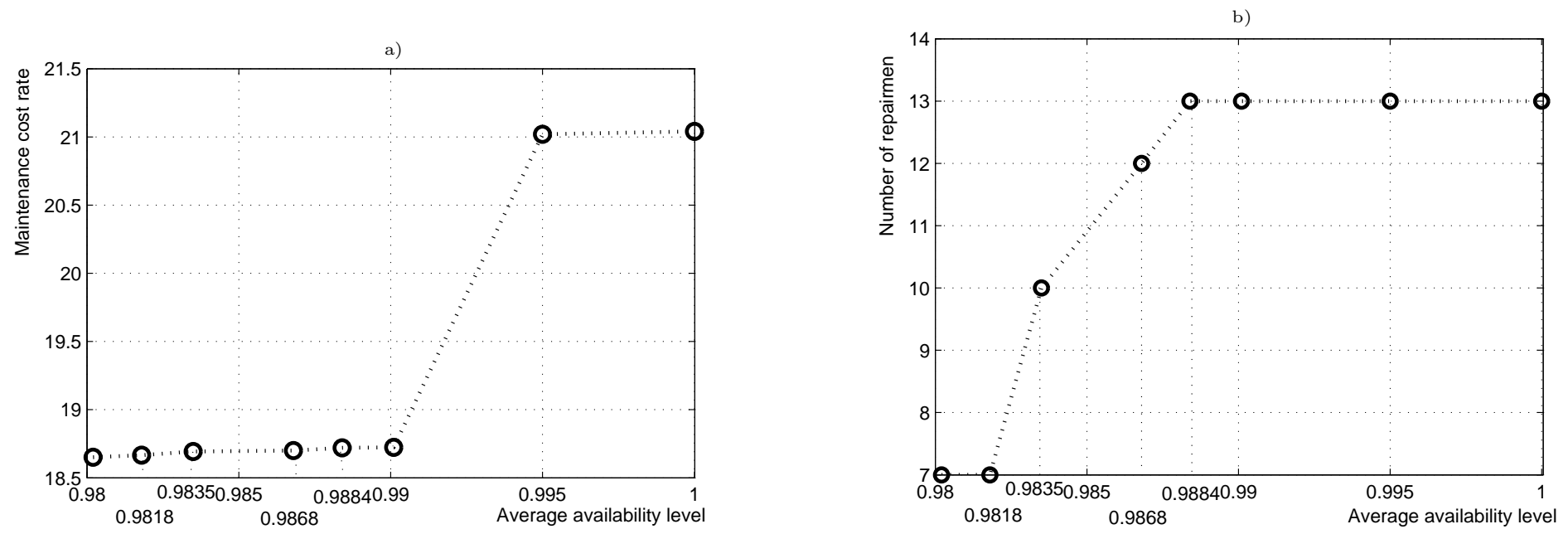

Figure 9: Impact of required average availability level on (a) the total maintenance cost rate and (b) the number of necessary repairmen

\subsection{Maintenance planning \& grouping with multi-availability level con- straint}

Assume now that the system has to serve two missions for which each mission requires a minimum average availability level. More precisely:

- Mission 1: only 5 time units are allowed for preventive maintenance during the mission interval $[0,300]$ (the required average availability level is 0.9833 );

- Mission 2: during the mission $(300,605]$, only 6 time units are allowed for preventive maintenance (the required average availability level for this mission is 0.980$)$.

If we look at the global horizon interval [ 0605$]$, the total duration allowed for maintenance is 11 time units. However the optimal maintenance planning above for which the required average availability level $A_{0}=0.9818$ (total maintenance duration allowed is 11 time units) is no longer useable since it does not reach the average availability level required by missions 1 and 2 . 
By integrating this multi-availability level constraint, the proposed maintenance approach provides a new optimal maintenance planning which is reported in Table.6

\begin{tabular}{ccccc}
\hline Group components & Optimal date $t_{G}$ & $Q_{G S^{*}}$ & $d_{G}$ & Necessary repairmen $m^{*}$ \\
\hline$\{1,2,4 \ldots, 9\}$ & 166.28 & & 5 & 5 \\
$\{3,10, \ldots, 20\}$ & 328.20 & & 6 & 9 \\
\hline
\end{tabular}

Table 6: Grouping with multi-availability level constraint

It is clear that the optimal maintenance planning for this case is different from the one for which only one availability level contraint (one mission with $A_{0}^{1}=0.9818$ ). More precisely, both the structure of each group and its optimal maintenance date are changed when considering multi-availability level constraint. It should be noticed that the number of necessary repairmen is also changed.

\subsection{Maintenance planning \& grouping with both availability and limited repairmen constraint}

From a practical point of view, the system can be is required to operate with a given average availability level and the maintenance teams are usually limited. To study the joint impacts of availability and limited repairmen constraint, only one mission is herein considered. Different required average availability levels for the mission are then studied. For each required average availability level, the numbers of repairmen are varied from 1 to 15 . Given a required average availability level and a number of available repairmen, we try to find an optimal maintenance planning. The obtained results are reported in Table 7.

\begin{tabular}{|c|c|c|c|c|c|c|c|}
\hline $\begin{array}{c}\text { Required average availability } \\
\text { level } A_{0}^{1}\end{array}$ & $\begin{array}{l}\text { Repairmen } \\
\text { constraint }\end{array}$ & Optimal solution & $t_{G}$ & $d_{G}$ & $Q_{G S^{*}}$ & $D_{G S^{*}}$ & $\begin{array}{c}\text { Necessary } \\
\text { repairmen } m^{*}\end{array}$ \\
\hline \multirow{4}{*}{0.9884} & $m<11$ & \multicolumn{6}{|c|}{ no solution } \\
\hline & $\mathrm{m}=11$ or $\mathrm{m}=12$ & $G_{1}=\{1, \ldots, 20\}$ & 241.45 & 7 & 391.74 & 7 & 11 \\
\hline & \multirow{2}{*}{$m \geq 13$} & $G_{1}=\{1\}$ & 0 & 1 & \multirow{2}{*}{398.76} & \multirow{2}{*}{7} & \multirow{2}{*}{13} \\
\hline & & $G_{2}=\{2, \ldots, 20\}$ & 249.06 & 6 & & & \\
\hline \multirow{7}{*}{0.9835} & $m<8$ & & & solv & & & \\
\hline & \multirow{2}{*}{$\mathrm{m}=8$} & $G_{1}=\{1\}$ & 0 & 1 & \multirow{2}{*}{383.76} & \multirow{2}{*}{10} & \multirow{2}{*}{8} \\
\hline & & $G_{2}=\{2, \ldots, 20\}$ & 249.06 & 9 & & & \\
\hline & \multirow{2}{*}{$\mathrm{m}=9$} & $G_{1}=\{1,2,4,5,6,7,9,19\}$ & 159.82 & 4 & \multirow{2}{*}{416.50} & \multirow{2}{*}{10} & \multirow{2}{*}{9} \\
\hline & & $G_{2}=\{3,8,10, \ldots, 18,20\}$ & 304.27 & 6 & & & \\
\hline & \multirow{2}{*}{$m \geq 10$} & $G_{1}=\{1,2,4,5,6,7,9\}$ & 156.58 & 4 & \multirow{2}{*}{419.57} & \multirow{2}{*}{10} & \multirow{2}{*}{10} \\
\hline & & $G_{2}=\{3,8,10, \ldots, 20\}$ & 305.55 & 6 & & & \\
\hline
\end{tabular}

Table 7: Optimal maintenance planning with both availability and repairmen constraint

The results show that:

- under a given required average availability level a maintenance planning can be established only for a high enough number of repairmen. In fact, the number of necessary repairmen is bounded. The 
lower bound corresponds to the minimum number of repairmen for which a maintenance planning can be constructed. The upper bound corresponds to the optimal number of repairmen for which the maintenance cost is the lowest. For example, when $A_{0}^{1}=0.9835$ (the average availability level is required to be not lower than 0.9835 , the lower and upper bound are 8 and 10 respectively. If the number of repairmen is lower than $8(m<8)$, no maintenance planning can be established. Maintenance planning and cost savings remain unchanged when $m \geq 10$. It should be noticed that the upper bound of repairmen is lower than the maximum number of maintenance activities in a group, see for example, when $A_{0}^{1}=0.9884$ ) we need only 13 repairmen to execute a group of 19 maintenance activities (group $\left.G_{2}=(2,3, \ldots, 20)\right)$ with a minimum execution duration;

- when the number of repairmen is in the bounded interval, an increase of repairmen may lead to a better maintenance planning with lower maintenance cost.

\section{Conclusions}

In this work, a dynamic maintenance grouping approach is proposed for multi-component systems. The rolling horizon approach is developed and used jointly with two optimization algorithms (GA and MULTIFIT) in order to find an optimal maintenance planning with availability level constraints and limited maintenance teams (repairmen). The proposed approach can also help to (i) provide the minimum number of repairmen to ensure that an establishable maintenance planning, which copes with given availability levels constraint, can be constructed; and (ii) determine the minimum number of repairmen that leads to an optimal maintenance planning satisfying the availability constraints with lowest maintenance cost. Moreover, thanks to the proposed grouping approach, through numerical results, impacts of availability constraints or/and limited repairmen on the maintenance planning are highlighted.

This paper is the development of our research in the framework of maintenance grouping approaches for multi-component systems with availability and maintenance resources constraints presented partially in [8]. Our future research work will focus on the development of the proposed approach for multi-component systems with complex structure.

\section{References}

[1] R. Aggoune. Minimizing the makespan for the flow shop scheduling problem with availability constraints. European Journal of Operational Research, 115(3):534-543, 2004.

[2] J. E. Baker. Adaptive selection methods for genetic algorithms. In Proceedings of the 1st International Conference on Genetic Algorithms, pages 101-111. L. Erlbaum Associates Inc., 1985.

[3] A. Bouvard, S. Artus, C. Berenguer, and V. Cocquempot. Condition-based dynamic maintenance operations planning and grouping. application to comercial heavy vehicules. Reliability Engineering and System Safety, 96(6):601 - 610, 2011. 
[4] D.-I. Cho and M. Parlar. A survey of maintenance models for multi-unit systems. European Journal of Operational Research, 51(1):1-23, 1991.

[5] S. Chung, F. Chan, and H. Chan. A modified genetic algorithm approach for scheduling of perfect maintenance in distributed production scheduling. Engineering Applications of Artificial Intelligence, 22(7):1005-1014, 2009.

[6] J. E. Coffman, M. Garey, and D. Johnson. An application of bin-packing to multiprocessor scheduling. SIAM Journal on Computing, 7:1, 1978.

[7] P. Do Van, A. Barros, C. Berenguer, K. Bouvard, and F. Brissaud. Dynamic grouping maintenance strategy with time limited opportunities. Reliability Engineering and System Safety, 120:51-59, 2013.

[8] P. Do Van, H. Vu, A. Barros, and C. Berenguer. Grouping maintenance strategy with availability constraint under limited repairmen. In 8th IFAC International Symposium on Fault Detection, Supervision and Safety for Technical Processes, SAFEPROCESS-2012, August 2012, Mexico city, Mexico, pages 486-491, 2012.

[9] G. Galante and G. Passannanti. An exact algorithm for preventive maintenance planning of seriesparallel systems. Reliability Engineering and System Safety, 94(10):1517 - 1525, 2009.

[10] J. Holland. Adaptation in natural and artificial systems. The University of Michigan Press, Ann Arbor, 1975.

[11] J. Kaabi and Y. Harrath. A survey of parallel machine scheduling under availability constraints. International Journal of Computer and Information Technology, 3(2):238-245, 2014.

[12] M. Kunde and H. Steppat. First fit decreasing scheduling on uniform multiprocessors. Discrete Applied Mathematics, 10(2):165 - 177, 1985.

[13] C. Lapa, C. Pereira, and M. de Barros. A model for preventive maintenance planning by genetic algorithms based in cost and reliability. Reliability Engineering and System Safety, 91(2):223-240, 2006.

[14] D. Lie. Fuzzy job shop scheduling problem with availability constraints. Computers and Industrial Engineering, 58(4):610-617, 2010.

[15] Y. Liu and H. Huang. Optimal selective maintenance strategy for multi-state systems under imperfect maintenance. IEEE Transactions On Reliability, 59(2):356 - 367, 2010.

[16] L. X. Min, W. J. Yong, Y. Yuan, and X. W. Yan. Multiobjective optimization of preventive maintenance schedule on traction power system in high-speed railway. In Reliability and Maintainability Symposium, 2009. RAMS 2009. Annual, pages 365-370. IEEE, 2009.

[17] K. Moghaddam and J. Usher. Sensitivity analysis and comparison of algorithms in preventive maintenance and replacement scheduling optimization models. Computers and Industrial Engineering, 61(1):64 - 75, 2011. 
[18] R. Nicolai and R. Dekker. Optimal maintenance of multi-component systems: a review. Complex System Maintenance Handbook, London: Springer, pages 263-286, 2008.

[19] M. Nourelfath and D. Ait-Kadi. Optimization of series-parallel multi-state systems under maintenance policies. Reliability Engineering and System Safety, 92(12):1620-1626, 2007.

[20] L. Radouane, C. Alaa, and A. Djamil. Opportunistic policy for optimal preventive maintenance of a multi-component system in continuous operating units. Computers and Chemical Engineering, 9(9):1499-1510, 2009.

[21] K. Rahman and S. Ahmed. Performance analysis of genetic algorithm for solving the multiple-choice multi-dimensional knapsack problem. International Journal of Recent Trends in Engineering, 2(2):103$105,2009$.

[22] C. R. Reeves and C. C. Wright. Genetic algorithms and the design of experiments. In Evolutionary Algorithms, pages 207-226. Springer, 1999.

[23] S. Ross. Stochastic Processes. Wiley Series in Probability and Statistics. John Wiley \& Sons, Inc., 1996.

[24] M. Shafiee and M. Finkelstein. An optimal age-based group maintenance policy for multi-unit degrading systems with application. Reliability Engineering and System Safety, 134:230-238, 2015.

[25] B. Shetty, G. Sekhon, O. Chawla, and K. Kurien. Optimization of maintenance facility for a repairable system subject to availability constraint. Microelectronics Reliability, 28(6):893-896, 1988.

[26] A. Van Horenbeek and L. Pintelon. A dynamic predictive maintenance policy for complex multicomponent systems. Reliability Engineering and System Safety, 120:39 - 50, 2013.

[27] A. Volkanovski, B. Mavko, T. Bosevski, A. Causevski, and M. Cepin. Genetic algorithm optimisation of the maintenance scheduling of generating units in a power system. Reliability Engineering and System Safety, 93(6):779-789, 2008.

[28] H.-C. Vu, P. Do, A. Barros, and C. Berenguer. Maintenance grouping strategy for multi-component systems with dynamic contexts. Reliability Engineering and System Safety, 132:233-249, 2014.

[29] H.-C. Vu, P. Do, A. Barros, and C. Berenguer. Maintenance planning and dynamic grouping for multicomponent systems with positive and negative economic dependencies. IMA Journal of Management Mathematics, 23:145-170, 2015.

[30] R. Wildeman, R. Dekker, and A. Smit. A dynamic policy for grouping maintenance activities. European Journal of Operational Research, 99:530-551, 1997. 